VNU Journal of Science: Legal Studies Journal homepage: https://js.vnu.edu.vn/LS

\title{
Original Article \\ The Issue of Compensation for Damage Caused by Violations of Competition Law in Vietnam
}

\author{
Tran Anh Tu*, Trinh Van Hung \\ VNU School of Law, 144 Xuan Thuy, Cau Giay, Hanoi, Vietnam
}

Received 07 January 2021

Revised 14 February 2021; Accepted 26 March 2021

\begin{abstract}
In Viet nam, current legal provisions related to the compensation for damages caused by the violation of competition law, are limited and have some irrelevant issues.This fact has greatly influenced on settlement of disputes raised from competition relations - A type of dispute is forseen to occur in the near future. The following article contributes to outline a legal framework on compensation for damages caused by violations of competition law, at the same time, analyzes and evaluates some shortcomings of the current regulations on the basis of comparision to practical demand for the purpose of providing some orientations and solutions to perfect these regulations.

Keywords: Competition, competition law, violations of competition law, civil liability.
\end{abstract}

\footnotetext{
${ }^{*}$ Corresponding author.

E-mail address: tuta@vnu.edu.vn

https://doi.org/10.25073/2588-1167/vnuls.4347
} 


\title{
Bồi thường thiệt hại do hành vi vi phạm pháp luật cạnh tranh gây ra tại Việt Nam
}

\author{
Trần Anh Tú *, Trịnh Văn Hưng \\ Khoa Luật, Đại học Quốc gia Hà Nội, 144 Xuân Thủy, Cầu Giấy, Hà Nội, Việt Nam \\ Nhận ngày 07 tháng 01 năm 2021 \\ Chỉnh sửa ngày 14 tháng 02 năm 2021; Chấp nhận đăng ngày 26 tháng 3 năm 2021
}

\begin{abstract}
Tóm tắt: Tại Việt Nam hiện nay, các quy định pháp luật có liên quan tới vấn đề bồi thường thiệt hại do hành vi vi phạm pháp luật cạnh tranh gây ra còn nhiều hạn chế và khiếm khuyết và thực trạng này ảnh hưởng lớn tới việc giải quyết các tranh chấp do quan hệ cạnh tranh mang lại - Một dạng tranh chấp được dự báo sẽ diễn ra ngày càng nhiều trong thời gian tới. Bài viết dưới đây góp phần phác thảo khung pháp lý về bồi thường thiệt hại do hành vi vi phạm luật cạnh tranh gây ra, đồng thời, phân tích, đánh giá những hạn chế của các quy định pháp luật hiện hành trên cơ sở đối chiếu với những vấn đề mà thực tiễn đặt ra để từ đó có những định hướng và giải pháp nhằm hoàn thiện các quy định này.
\end{abstract}

Từ khóa: Cạnh tranh, pháp luật cạnh tranh, hành vi vi phạm pháp luật cạnh tranh, bồi thường thiệt hại ngoài hợp đồng.

Tại Việt Nam hiện nay, việc giải quyết yêu cầu bồi thường thiệt hại do hành vi vi phạm pháp luật cạnh tranh gây ra được Luật Cạnh tranh (2018) dẫn chiếu tới các quy định của pháp luật dân sự về bồi thường thiệt hại ngoài hợp đồng. Về nguyên tắc, mọi tổ chức, cá nhân cho rằng quyền và lợi ích hợp pháp của mình bị bị xâm phạm bởi hành vi vi phạm pháp luật cạnh tranh đều có quyền khởi kiện để yêu cầu bên có hành vi vi phạm phải bồi thường thiệt hại cho mình. Tuy nhiên, khung pháp lý về giải quyết yêu cầu bồi thường thiệt hại do hành vi vi phạm pháp luật cạnh tranh ở Việt Nam hiện nay còn nhiều hạn chế như: Quy trình giải quyết không rõ ràng, đồng bộ gây khó khăn cho thiết chế có thẩm quyền khi xử lý; thiếu các đảm bảo cần thiết cho tổ chức, cá nhân bị thiệt hại khi thực hiện tố quyền; các quy định không phù hợp với tính chất đặc thù của thiệt hại trong cạnh tranh,...

\footnotetext{
* Tác giả liên hệ.

Địa chỉemail: tuta@vnu.edu.vn

https://doi.org/10.25073/2588-1167/vnuls.4347
}

Ngày 10/3/2020, Tòa án Nhân dân cấp cao tại Thành phố Hồ Chí Minh đã mở phiên tòa xét xử phúc thẩm vụ kiện "tranh chấp bồi thường thiệt hại ngoài hợp đồng" giữa nguyên đơn là Công ty Cổ phần Ánh Dương Việt Nam (Vinasun) và bị đơn là Công ty Trách nhiệm hữu hạn Grab (Grab). Với quyết định giữ nguyên kết quả của bản án sơ thẩm, bản án phúc thẩm mà Tòa án Nhân dân cấp cao tại Thành phố Hồ Chí Minh đưa ra đã khép lại vụ tranh chấp kéo dài hơn hai năm với không ít sự quan tâm của dư luận xã hội nhưng lại không nhận được sự đồng tình của tất cả các bên liên quan, từ nguyên đơn tới bị đơn và kể cả Viện Kiểm sát Nhân dân (hai cấp). Xét về bản chất, vụ tranh chấp giữa Vinasun và Grab là tranh chấp phát sinh từ quan hệ cạnh tranh và sự "bối rối" của các cơ quan tố tụng trong việc giải quyết yêu cầu bồi thường thiệt hại của nguyên đơn đã phản ánh rất rõ những bất cập trong các quy định pháp luật hiện nay về bồi thường thiệt hại do hành vi vi phạm pháp luật cạnh tranh gây ra. 
Việc hoàn thiện các quy định pháp luật nhằm tạo ra một cơ chế pháp lý thích hợp, hiệu quả để giải quyết yêu cầu bồi thường thiệt hại do hành vi vi phạm pháp luật cạnh tranh gây ra ở Việt Nam hiện nay là rất cần thiết, bởi lẽ cùng với sự gia tăng của các hành vi vi phạm pháp luật cạnh tranh trên thị trường, những yêu cầu như vậy trong thời gian tới sẽ diễn ra ngày càng nhiều, đồng thời còn nhằm đảm bảo cho chúng ta có thể thực thi tốt các nội dung đã cam kết về chính sách sách và pháp luật cạnh tranh trong các hiệp định thương mại tự do mà Việt Nam đã ký kết và tham gia trong thời gian qua ${ }^{1}$.

\section{Cơ sở pháp lý để giải quyết yêu cầu bồi thường thiệt hại do hành vi vi phạm pháp luật cạnh tranh gây ra ở Việt Nam hiện nay}

Theo quy định của pháp luật Việt Nam hiện nay, trong quá trình điều tra, xử lý vụ việc cạnh tranh, Ủy ban Cạnh tranh Quốc gia không giải quyết yêu cầu bồi thường thiệt hại do hành vi vi phạm pháp luật cạnh tranh gây ra. Điều 110 Luật Cạnh tranh (2018) quy định: "Tổ chức, cá nhân có hành vi vi phạm pháp luật về cạnh tranh gây thiệt hại đến lợi ích của Nhà nước, quyền và lợi ích hợp pháp của tổ chức, cá nhân khác thì phải bồi thường thiệt hại theo quy định của pháp luật".

Như vậy, sau khi quyết định xử lý vụ việc cạnh tranh có hiệu lực, mọi tổ chức, cá nhân bị thiệt hại bởi hành vi vi phạm pháp luật cạnh tranh có quyền khởi kiện tại tòa án (tòa dân sự theo thẩm quyền) để yêu cầu bồi thường thiệt hại căn cứ vào các quy định của Bộ luật Dân sự

\footnotetext{
${ }^{1}$ Theo yêu cầu của Hiệp định đối tác toàn diện và tiến bộ xuyên Thái Bình Dương (CPTPP), các quốc gia thành viên phải có Luật hoặc các biện pháp khác (ví dụ như các quy định, thủ tục) cho phép các doanh nghiệp hoặc cá nhân (kể cả từ các nước thành viên CPTPP khác) có hành động pháp lý để đòi bồi thường cho tổn thất hoặc thiệt hại do hành vi vi phạm pháp luật cạnh tranh quốc gia. Xem thêm nội dung Hiệp định đối tác toàn diện và tiến bộ xuyên Thái Bình Dương [1].
}

(2015) về bồi thường thiệt hại ngoài hợp đồng. Về nguyên tắc, tổ chức, cá nhân bị thiệt hại cũng có thể khởi kiện ngay tại Tòa án để yêu cầu bồi thường mà không cần phải khiếu nại vụ việc tới Ủy ban Cạnh tranh Quốc gia.

Theo quy định tại Điều 275 Bộ luật Dân sự (2015), một trong những căn cứ làm phát sinh nghĩa vụ dân sự là việc "gây thiệt hại do hành vi trái pháp luật” và tương ứng với căn cứ này là các quy định tại Chương XX, Phần thứ ba Bộ luật này về "Trách nhiệm bồi thường thiệt hại ngoài hợp đồng". Theo khoản 1, Điều 584 Bộ luật Dân sự (2015): "Người nào có hành vi xâm phạm tính mạng, sức khỏe, danh dự, nhân phẩm, uy tín, tài sản, quyền, lợi ích hợp pháp khác của người khác mà gây thiệt hại thì phải bồi thường, trừ trường hợp bộ luật này, luật khác có liên quan quy định khác". Căn cứ vào các quy định hiện nay của Bộ luật Dân sự (2015), trách nhiệm bồi thường thiệt hại ngoài hợp đồng phát sinh khi có đủ các điều kiện sau: thứ nhât, có thiệt hại thực tế xảy ra; thứ hai, hành vi gây thiệt hại là hành vi trái pháp luật; thứ ba, có mối quan hệ nhân quả giữa hành vi trái pháp luật và thiệt hại thực tế xảy ra; thứ tư, người gây thiệt hại có lỗi "cố ý" hoặc "vô ý".

Bên cạnh trách nhiệm bồi thường thiệt hại của thương nhân do thực hiện hành vi vi phạm pháp luật cạnh tranh, khoản 1 Điều 113 Luật Cạnh tranh (2018) còn có quy định: "Trường hợp cơ quan nhà nước thực hiện hành vi quy định tại khoản 1 Điều 8 của Luật này, Ủy ban Cạnh tranh Quốc gia có trách nhiệm yêu cầu cơ quan nhà nước chấm dứt hành vi vi phạm và khắc phục hậu quả. Cơ quan nhà nước được yêu cầu phải chấm dứt hành vi vi phạm, khắc phục hậu quả và bồi thường thiệt hại theo quy định của pháp luật". Như vậy, trong quá trình thực hiện chức năng quản lý nhà nước đối với hoạt động sản xuất, kinh doanh, nếu người thi hành công vụ, cơ quan nhà nước vi phạm các điều cấm kể trên mà gây thiệt hại cho tổ chức, cá nhân thì tổ chức, cá nhân bị thiệt hại cũng có quyền yêu cầu bồi thường thiệt hại theo quy định của pháp luật. 


\section{Phân tích, bình luận và một số kiến nghị nhằm hoàn thiện pháp luật về bồi thường thiệt hại do hành vi vi phạm pháp luật cạnh tranh gây ra ở Việt Nam hiện nay}

\subsection{Về thẩm quyền và thủ tục giải quyết yêu cầu bồi thuờng thiệt hại do hành vi vi phạm pháp luật canh tranh gây ra}

Việc Luật Cạnh tranh (2004) và Luật Cạnh tranh (2018) đều dẫn chiếu việc giải quyết yêu cầu bồi thường thiệt hại do hành vi vi phạm pháp luật cạnh tranh gây ra đến các quy định của pháp luật dân sự cũng có nghĩa là ở Việt Nam hiện nay thẩm quyền giải quyết loại yêu cầu này thuộc về hệ thống tòa tư pháp, cụ thể là tòa dân sự.

Theo thông lệ chung trên thế giới, yêu cầu bồi thường thiệt hại do hành vi vi phạm pháp luật cạnh tranh gây ra có liên quan trực tiếp đến quyền và lợi ích hợp pháp của các tổ chức, cá nhân nên việc giao cho cơ quan tư pháp giải quyết là hoàn toàn hợp lý $[2$, tr.8]. Tại Liên minh Châu Âu, Quy định chi tiết thực thi chế định kiện đòi bồi thường thiệt hại trong các vụ việc cạnh tranh được Hội đồng Châu Âu thông qua ngày $10 / 11 / 2014$ và được Chủ tịch Nghi viện Châu Âu ký ban hành ngày $26 / 11 / 2014 .{ }^{2}$ Theo Quy định này thì:"'Quyết định cuối cùng của cơ quan cạnh tranh tại một quốc gia trong đó xác định hành vi vi phạm pháp luật cạnh tranh sẽ tự động được coi là bằng chứng về hành vi vi phạm trước toà án của quốc gia đó, nơi mà hành vi vi phạm được thực hiện, để làm cơ sở giải quyết việc kiện đòi bồi thường; các bị hại sẽ có ít nhất một năm, kể từ ngày cơ quan cạnh tranh ra quyết định cuối cùng, để thực hiện quyền kiện đòi bồi thường thiệt hại" [3].

Tại Việt Nam, trong "Báo cáo tiếp thu, giải trình ý kiến của Ưy ban Thường vụ Quốc hội và các Ủy ban của Quốc hội đối với dự thảo Luật

\footnotetext{
${ }^{2}$ Sự ra đời của Quy định này là nhằm thực thi một cách có hiệu quả các quy định pháp luật chung về cạnh tranh của Liên minh Châu Âu thông qua việc tạo điều kiện dễ dàng hơn cho các tổ chức, cá nhân bị thiệt hại do hành vi vi phạm pháp luật cạnh tranh gây ra thực hiện quyền kiện đòi bồi thường.
}

Cạnh tranh (sửa đổi)" năm 2017, trước ý kiến cho rằng đối với các vụ việc hạn chế cạnh tranh và tập trung kinh tế, việc giải quyết về mặt hành chính cần được thực hiện theo quy định của Luật Cạnh tranh, ngoài ra các bên có thể đưa ra tòa án để giải quyết yêu cầu bồi thường thiệt hại theo thủ tục tố tụng dân sự, đồng thời đề nghi bổ sung quyền của tổ chức, cá nhân trong việc lựa chọn khởi kiện ra toà án, tránh cách hiểu việc giải quyết vụ việc cạnh tranh chỉ được tiến hành theo trình tự, thủ tục quy định tại Luật Cạnh tranh, Bộ Công Thương đã giải trình rằng việc đó là không cần thiết vì: "Bộ luật Tố tụng dân sự đã ghi nhận quyền của cơ quan, tổ chức, cá nhân trong việc khởi kiện vụ án dân sự, yêu cầu giải quyết việc dân sự tại Toà án có thẩm quyền để bảo vệ quyền và lợi ích hợp pháp của mình hoặc của người khác. Như vậy, đây là quyền đã được ghi nhận, thuộc phạm vi quy định của Bộ luật Tố tụng dân sự; việc Luật Canh tranh không quy định tổ chức, cá nhân có quyền lựa chọn giải quyết vụ việc theo thủ tục tố tụng dân sự là không trái và không làm triệt tiêu quyền này" $[4, \operatorname{tr} .10]$.

Cách giải thích này của Bộ Công thương cho phép chúng ta hiểu rằng mọi tổ chức, cá nhân bị thiệt hại bởi hành vi vi phạm pháp luật cạnh tranh đều có quyền khởi kiện ngay tại tòa án để yêu cầu bồi thường thiệt hại mà bỏ qua vai trò giải quyết của cơ quan cạnh tranh. Tuy nhiên, tại Việt Nam hiện nay, việc giải quyết yêu cầu bồi thường thiệt hại do hành vi vi phạm pháp luật cạnh tranh gây ra tại Tòa án mà không cần tới sự tham gia của cơ quan canh tranh là không hợp lý bởi hai lý do:

- Thứ nhất: Căn cứ pháp lý làm phát sinh nghĩa vụ bồi thường thiệt hại trong trường hợp này được xác định là hành vi gây thiệt hại trái pháp luật theo quy định tại khoản 5 Điều 275 Bộ luật Dân sự (2015). Như vậy, tòa án trước khi xác định trách nhiệm bồi thường cho bị đơn phải tuyên bố được rằng bi đơn đã có hành vi trái pháp luật gây thiệt hại cho nguyên đơn. Hành vi trái pháp luật ở đây là hành vi vi phạm pháp luật cạnh tranh. Cũng cần lưu ý rằng, hành vi vi phạm pháp luật cạnh tranh theo Luật Cạnh tranh (2018) sẽ bao gồm ba loại là hành vi vi phạm pháp luật chống cạnh tranh không lành 
mạnh, hành vi vi phạm pháp luật chống hạn chế cạnh tranh và hành vi vi phạm quy định về tập trung kinh tế vốn khác nhau về bản chất. Khi cơ quan có thẩm quyền ra phán quyết một hành vi cạnh tranh nào đó có vi phạm pháp luật cạnh tranh hay không phải căn cứ vào các chứng cứ để chứng minh. Trong khi đó, bản thân tòa án không có công cụ điều tra, chỉ có thể yêu cầu các bên cung cấp chứng cứ mà không thể tự mình điều tra, thu thập chứng cứ để chứng minh. Nội dung chứng minh trong trường hợp vụ việc hạn chế cạnh tranh hay tập trung kinh tế là rất phức tạp, từ việc xác định thị trường liên quan, xác định quyền lực thị trường và khả năng gây hạn chế cạnh tranh của doanh nghiệp (nhóm doanh nghiệp) trên thị trường liên quan mới có thể chứng minh được hành vi vi phạm và chủ thể thực hiện hành vi vi phạm. Như vậy, để tòa án có thể ra phán quyết về tính trái pháp luật của một hành vi cạnh tranh và giải quyêt yêu cầu bồi thường thiệt hại cho nguyên đơn, nhất thiết tòa án phải được sự hỗ trợ của cơ quan cạnh tranh trong việc điều tra để cung cấp chứng cứ chứng minh [5].

- Thú hai: Với chức năng bảo vệ thị trường trước các hành vi phản cạnh tranh, phá hủy cạnh tranh, cơ quan cạnh tranh của tất cả các quốc gia trên thế giới đều được thiết kế với vai trò như một cơ quan "gác cửa" cho mọi hoạt động cạnh tranh diễn ra trên thị trường. Cơ quan này có thẩm quyền can thiệp, xử lý về mặt hành chính đối với bất kỳ hành vi cạnh tranh nào có thể gây tổn hại cho thị trường hoặc áp dụng các biện pháp cần thiết nhằm khắc phục những biến dạng, khôi phục lại nguyên trạng thị trường như trước khi hành vi vi phạm gây ra. Do đó, nếu chỉ giải quyết yêu cầu bồi thường thiệt hại do hành vi vi phạm pháp luật cạnh tranh gây ra tại Tòa án, bỏ qua vai trò "gác cửa" của cơ quan cạnh tranh sẽ làm mất đi giá trị của Luật Cạnh tranh.

Với những lý do kể trên, trong bối cảnh ở Việt Nam hiện nay, việc Tòa dân sự hay bất kỳ một Tòa tư pháp nào giải quyết yêu cầu bồi thường thiệt hại do hành vi vi phạm pháp luật cạnh tranh gây ra mà không cần đến cơ quan cạnh tranh là không thể và không hợp lý. Nhưng Tòa án lại không thể từ chối nghĩa vụ xét xử của mình khi tổ chức, cá nhân khởi kiện. Để bảo vệ công lý, bảo vệ quyền con người, quyền công dân, quyền và lợi ích hợp pháp của các tổ chức, cá nhân, Điều 4 Bộ luật Tố tụng Dân sự (2015) và khoản 2 Điều 14 Bộ luật Dân sự 2015 đều có quy định tòa án không được từ chối giải quyết vụ việc dân sự vì lý do chưa có điều luật để áp dụng. Do đó, giải pháp đưa ra trong trường hợp này là chúng ta phải thiết lập mối quan hệ pháp lý chặt chẽ giữa cơ quan cạnh tranh và Tòa án để trên cơ sở đó:

+ Thứ nhất: Trong trường hợp nếu tổ chức, cá nhân bị thiệt hại thực hiện quyền khiếu nại đến cơ quan cạnh tranh có kèm theo yêu cầu đòi bồi thường thiệt hại, cơ quan cạnh tranh sẽ thụ lý, điều tra và xử lý theo thẩm quyền (xử lý hành chính) sau đó chuyển yêu cầu bồi thường thiệt hại cho tòa án giải quyết hoặc hướng dẫn cho bên bị thiệt hại sử dụng các kết quả xử lý của mình để khởi kiện tại tòa án yêu cầu bồi thường thiệt hại. Với các quy định pháp luật hiện nay, về nguyên tắc tòa án có thể thừa nhận giá trị pháp lý của quyết định xử lý vụ việc cạnh tranh mà cơ quan cạnh tranh đã ban hành hoặc tự mình độc lập xác định tính trái pháp luật của hành vi trong quá trình giải quyết yêu cầu bồi thường thiệt hại. Tuy nhiên, như đã phân tích ở trên, trong trường hợp này tòa án cần thừa nhận kết quả xử lý của cơ quan cạnh tranh làm căn cứ cho việc giải quyết yêu cầu bồi thường thiệt hại của mình.

+ Thứ hai: Trong trường hợp nếu tổ chức, cá nhân bị thiệt hại thực hiện ngay quyền khởi kiện tại tòa án mà không thực hiện quyền khiếu nại đển cơ quan cạnh tranh, tòa án phải có quyền yêu cầu cơ quan cạnh tranh tiến hành điều tra và ra quyết định xử lý, xác định rõ tính trái pháp luật của hành vi làm căn cứ cho tòa án giải quyết yêu cầu bồi thường thiệt hại. Trong quá trình xử lý hành chính, cơ quan cạnh tranh có thể áp dụng các chế tài hành chính và các biện pháp khắc phục về mặt thị trường để đảm bảo chức năng quản lý nhà nước về cạnh tranh của mình. 


\subsection{Về vấn đề bồi thường thiệt hại do hành vi vi phạm pháp luật cạnh tranh của co quan nhà nước gây ra}

Quy định về trách nhiệm bồi thường thiệt hại của cơ quan nhà nước do vi phạm pháp luật cạnh tranh tại khoản 1 Điều 113 cùng với quy định tại khoản 3 Điều 2 về việc mở rộng đối tượng áp dụng của Luật Cạnh tranh đối với các "Cơ quan, tổ chức, cá nhân trong nước và nước ngoài có liên quan" là một điểm mới của Luật Cạnh tranh (2018) so với Luật Cạnh tranh (2004) nhằm đảm bảo thực thi các quy định cấm tại khoản 1 Điều 8 đối với các cơ quan nhà nước khi thực hiện hành vi gây cản trở cạnh tranh trên thị trường, bao gồm: a) Ép buộc, yêu cầu, khuyến nghị doanh nghiệp, cơ quan, tổ chức, cá nhân phải thực hiện hoặc không thực hiện việc sản xuất, mua, bán hàng hóa, cung ứng, sử dụng dịch vụ cụ thể hoặc mua, bán hàng hóa, cung ứng, sử dụng dịch vụ với doanh nghiệp cụ thể, trừ hàng hóa, dịch vụ thuộc lĩnh vực độc quyền nhà nước hoặc trong trường hợp khẩn cấp theo quy định của pháp luật; b) Phân biệt đối xử giữa các doanh nghiệp; c) Ép buộc, yêu cầu, khuyến nghị các hiệp hội ngành, nghề, tổ chức xã hội - nghề nghiệp khác hoặc các doanh nghiệp liên kết với nhau nhằm hạn chế cạnh tranh trên thị trường; d) Lợi dụng chức vụ, quyền hạn để can thiệp trái pháp luật vào hoạt động cạnh tranh". Có thể nói rằng, các quy định này của Luật Cạnh tranh (2018) là rất phù hợp, góp phần kiểm soát hiện tượng "Độc quyền hành chính" vốn diễn ra khá phổ biến ở Việt Nam hiện nay khi các cơ quan quản lý nhà nước thường có những hành vi can thiệp bất hợp lý vào hoạt động kinh doanh nhằm tạo ra "đặc lợi" cho doanh nghiệp (nhóm doanh nghiệp) này nhưng lại gây bất lợi cho các doanh nghiệp khác trong cạnh tranh [6, tr.808-819]. Tuy nhiên, khi xem xét trong tổng thể các quy định pháp luật có liên quan, có thể thấy quy định về trách nhiệm bồi thường thiệt hại của cơ quan nhà nước do vi phạm khoản 1 Điều 8 Luật Cạnh tranh sẽ khó thực thi trên thực tế, bởi lẽ̃: Điều 598 Bộ luật Dân sự (2015) về bồi thường thiệt hại do người thi hành công vụ gây ra quy định "Nhà nước có trách nhiệm bồi thường thiệt hại do hành vi trái pháp luật của người thi hành công vụ gây ra theo quy định của Luật trách nhiệm bồi thường của nhà nước". Trong khi đó, Điều 17 Luật Trách nhiệm bồi thường của Nhà nước (2017) quy định về phạm vi trách nhiệm bồi thường của nhà nước trong hoạt động quản lý hành chính chỉ xác định 14 trường hợp mà nhà nước có trách nhiệm phải bồi thường, trong đó không có trường hợp nào là hành vi bị cấm được mô tả tại khoản 1 Điều 8 Luật cạnh tranh (2018). Như vậy, để có thể thi hành được quy định tại khoản 1 Điều 113 làm cơ sở cho việc tổ chức, cá nhân yêu cầu bồi thường thiệt hại do hành vi vi phạm khoản 1 Điều 8 Luật Cạnh tranh (2018) của các cơ quan nhà nước thì Luật trách nhiệm bồi thường của Nhà nước (2017) cần được sửa đổi theo hướng quy định mở về các trường hợp, hành vi làm phát sinh trách nhiệm bồi thường của Nhà nước, cụ thể là: ngoài các trường hợp đã được liệt kê như hiện nay tại Điều 17 cần có thêm "các trường hợp khác mà pháp luật quy định" [7].

\subsection{Về việc xác dịnh thiệt hại do hành vi vi phạm pháp luật cạnh tranh gây ra}

Các loại thiệt hại được bồi thường theo trách nhiệm bồi thường thiệt hại ngoài hợp đồng được quy định từ Điều 589 - 593 Bộ luật Dân sự (2015) gồm có: 1) Thiệt hại do tài sản bị xâm phạm; 2) Thiệt hại do sức khỏe bị xâm phạm; 3) Thiệt hại do tính mạng bị xâm phạm; 4) Thiệt hại do danh dự, nhân phẩm, uy tín bị xâm phạm. Trong đó, thiệt hại do tài sản bị xâm phạm được xác định là: Tài sản bị mất, bị hủy hoại hoặc bị hư hỏng; lợi ích gắn liền với việc sử dụng, khai thác tài sản bị mất, bị giảm sút; chi phí hợp lý để ngăn chặn, hạn chế và khắc phục thiệt hại; thiệt hại khác do luật quy định. Thiệt hại do danh dự, nhân phẩm, uy tín bị xâm phạm được xác định bao gồm: Chi phí hợp lý để hạn chế, khắc phục thiệt hại; thu nhập thực tế bị mất hoặc bị giảm sút; thiệt hại khác do luật quy định.

So với các loại thiệt hại kể trên, thiệt hại trong cạnh tranh là một loại thiệt hại rất đặc thù, đó là các tổn thất về kinh tế do hành vi vi phạm pháp luật cạnh tranh gây ra. Các tổn thất này 
không phát sinh do tài sản bị mất mát, phá hủy, hư hỏng hay tính mạng, sức khỏe bị xâm hại mà là hậu quả trực tiếp của hành vi vi phạm pháp luật cạnh tranh, bao gồm: Các cơ hội kinh doanh bị bỏ lỡ; các khoản lợi nhuận và thu nhập bị mất hoặc giảm sút; các khoản lỗ phải gánh chịu; các chi phí phát sinh,... Do đó, việc xác định thiệt hại do hành vi vi phạm pháp luật cạnh tranh gây ra sẽ không hợp lý nếu chỉ căn cứ vào các quy định hiện tại trong Bộ luật Dân sự (2015).

Tại Hoa Kỳ, trong các vụ kiện đòi bồi thường thiệt hại do hành vi phản cạnh tranh gây ra, nguyên đơn buộc phải chỉ ra được thiệt hại mà họ đòi bồi thường, đây là loại thiệt hại đặc biệt gọi là "thiệt hại trong cạnh tranh". Điều 4, Đạo luật Clayton cho phép bồi thường thiệt hại cho "những người nào đã bị thiệt hại trong hoạt động kinh doanh hoặc thiệt hại về tài sản do một hành vi vi phạm pháp luật chống độc quyền gây ra..."[8].

Để bổ sung cho các quy định của Bộ luật Dân sự (2015), chúng tôi cho rằng Hội đồng thẩm phán Tòa tối cao nên có hướng dẫn riêng, chi tiết về "Thiệt hại do hành vi vi phạm pháp luật cạnh tranh gây ra" làm cơ sở cho việc xác định và giải quyết loại yêu cầu bồi thường này trong thực tế.

\subsection{Về múc bồi thường thiệt hại do hành vi vi phạm pháp luật cạnh tranh gây ra}

Đặc thù của hành vi vi phạm pháp luật cạnh tranh là có thể gây thiệt hại cùng lúc cho nhiều tổ chức, cá nhân khác nhau và trong nhiều trường hợp thiệt hại gây ra cho mỗi tổ chức, cá nhân là không lớn. Chính vì vậy, các tổ chức, cá nhân bị thiệt hại đôi khi không quá thiết tha với "tố quyền" kiện đòi bồi thường thiệt hại của mình. Trong khi đó, mức bồi thường thiệt hại ngoài hợp đồng được xác định theo các nguyên tắc quy định tại Điều 585, Bộ luật Dân sự (2015) sẽ không thể lớn hơn tổng thiệt hại thực tế của bên bị thiệt hại. Quy định về mức bồi thường ngang bằng như hiện nay là không phù hợp, không khuyến khích được các doanh nghiệp, đặc biệt là người tiêu dùng khởi kiện trong trường hợp bị thiệt hại bởi hành vi vi phạm pháp luật cạnh tranh [9, tr.48-52]. Ngoài ra, việc giới hạn mức bồi thường tổn thất về tinh thần không quá mười lần mức lương cơ sở do Nhà nước quy định (trừ trường hợp các bên có thỏa thuận khác) tại khoản 2 Điều 592 Bộ luật Dân sự (2015) cũng là không phù hợp trong trường hợp uy tín của doanh nghiệp bị mất, bị hủy hoại, giảm sút bởi hành vi vi phạm pháp luật cạnh tranh. Việc doanh nghiệp bị mất uy tín trong hoạt động kinh doanh sẽ làm mất đi năng lực cạnh tranh, vị thế của doanh nghiệp trên thị trường và kèm theo đó có thể là những khoản lợi nhuận khổng lồ bị mất hay những khoản lỗ lớn mà doanh nghiệp phải gánh chịu.

Kinh nghiệm tại Hoa Kỳ cho thấy để khuyến khích việc khởi kiện trong trường hợp này, đồng thời tăng tính răn đe đối với các hành vi vi phạm, Điều 4 Đạo luật Clayton đưa ra mức bồi thường có thể gấp ba lần thiệt hại thực tế cùng toàn bộ phí tổn cho việc theo đuổi vụ kiện, bao gồm cả chi phí hợp lý để thuê luật sư [8]. Tại Đài Loan, Điều 31 Luật Thương mại lành mạnh (2015) cũng có quy định trong trường hợp hành vi vi phạm là cố ý, theo yêu cầu của bên bị thiệt hại và căn cứ vào phạm vi ảnh hưởng của hành vi, tòa án có thể ra phán quyết buộc bồi thường lớn hơn mức tổn thất thực tế, miễn là mức ây không vượt quá ba lần thiệt hại thực tế được chứng minh [10].

Để khuyến khích việc khiếu nại, khởi kiện, đồng thời tăng tính răn đe đối với các hành vi vi phạm pháp luật cạnh tranh, mức bồi thường không thể áp dụng như trong Bộ luật Dân sự (2015) về bồi thường thiệt hại ngoài hợp đồng. Kinh nghiệm của một số quốc gia trên thế giới như Hoa Kỳ hay Đài Loan, như đã phân tích ở trên, có thể là những gợi ý cho Việt Nam trong việc xây dựng quy định riêng về mức bồi thường thiệt hại do hành vi vi phạm pháp luật cạnh tranh gây ra.

2.5. Về thời hiệu và cách tính thời hiệu khởi kiện yêu cầu bồi thuờng thiệt hại do hành vi vi phạm pháp luật cạnh tranh gây ra

Theo quy định tại Điều 77 và Điều 80 Luật Cạnh tranh (2018), thời hiệu khiếu nại vụ việc cạnh tranh là 02 năm tính từ thời điểm hành vi 
có dấu hiệu vi phạm pháp luật về cạnh tranh được thực hiện. Trong chế định bồi thường thiệt hại ngoài hợp đồng của Bộ luật Dân sự (2015), Điều 588 cũng quy định thời hiệu khởi kiện yêu cầu bồi thường thiệt hại là 03 năm nhưng kể từ ngày người có quyền yêu cầu biết hoặc phải biết quyền, lợi ích hợp pháp của mình bị xâm phạm.

Như vậy, theo quy định của Bộ luật Dân sự (2015), một hành vi vi phạm pháp luật có thể diễn ra từ rất lâu, song nếu hành vi đó gây ra thiệt hại cho người khác thì thời hiệu khởi kiện được tính từ thời điểm bên bị thiệt hại biết hoặc phải biết quyền và lợi ích hợp pháp của mình bị xâm hại chứ không phải tại thời điểm hành vi được thực hiện. Sự khác nhau trong cách tính thời hiệu khiếu nại giữa Luật Cạnh tranh (2018) và Bộ luật Dân sự (2015) sẽ dẫn đến tình huống thực tế là bên khiếu nại khi nhận thấy quyền và lợi ích hợp pháp của mình bị xâm phạm bởi hành vi vi phạm pháp luật cạnh tranh và tiến hành khởi kiện tại tòa án đòi bồi thường thiệt hại thì thời hiệu khởi kiện vẫn còn song thời hiệu để điều tra và xử lý hành vi vi phạm pháp luật cạnh tranh đã hết.

Chúng tôi cho rằng quy định về cách tính thời hiệu của Luật Cạnh tranh và Bộ luật Dân sự cần thiết phải được quy định lại một cách thống nhất để đảm bảo quyền khiếu nại/khởi kiện của tổ chức, cá nhân bị thiệt hại do hành vi vi phạm pháp luật cạnh tranh gây ra.

\section{Tài liệu tham khảo}

[1] Trung tâm WHO và Hội nhập - Phòng Thương mại và Công nghiệp Việt Nam, Hiệp định Đối tác Thương mại xuyên Thái Bình Dương, $<$ https://trungtamwto.vn/fta >, truy cập ngày 25.11.2020;

[2] UNCTAD (2000), Luật mẫu về cạnh tranh (Người dịch: Hoàng Xuân Bắc);

[3] Official Journal of the European Union, https://eur-lex.europa.eu/eli/dir/2014/104/oj, truy cập ngày 7/12/2020.

[4] Bộ Công Thương (2017), Báo cáo tiếp thu, giải trình ý kiến của Ủy ban Thường vụ Quốc hội và các Ưy ban của Quốc hội đối với Dự thảo Luật Cạnh tranh (sửa đổi), Hồ sơ Dự án Luật Cạnh tranh (sửa đồi);

[5] Trần Anh Tú, Về cơ chế đảm bảo quyền khiếu nại vụ việc cạnh tranh, Tạp chí Nghiên cứu Lập pháp, số 21, kỳ 1 - Tháng 11/2018;

[6] Phạm Duy Nghĩa (2004), Chuyên khảo Luật kinh tế, Nxb Đại học Quốc gia Hà Nội;

[7] Đỗ Văn Đại (2016), Phạm vi của Luật trách nhiệm bồi thường của Nhà nước, Tạp chí Nghiên cứu Lập pháp số 20 (324), tháng 10/2016;

[8] Bộ Tư pháp Hoa Kỳ, link:

https://www.justice.gov/atr/file/761131/download truy cập ngày 7/12/2020.

[9] Đào Ngọc Báu (2017), Bồi thường thiệt hại ngoài hợp đồng: Phân tích từ góc độ pháp luật cạnh tranh, Tạp chí Khoa học \& Công nghệ Việt Nam, số 19(8) 8.2017;

[10] Ủy ban Thương mại lành mạnh Đài Loan, http://www.ftc.gov.tw/internet/english/doc/docDe tail.aspx?uid=1295\&docid=13970, truy cập ngày 7/12/2020. 